Vrij Aldert (Orcid ID: 0000-0001-8647-7763)

\title{
Eliciting Information and Cues to Deceit through Sketching in Interpreter-Based Interviews
}

\author{
Aldert Vrij \\ Sharon Leal \\ Ronald P. Fisher \\ Samantha Mann \\ Eunkyung Jo \\ Alla Shaboltas \\ Maria Khaleeva \\ Juliana Granskaya \\ Kate Houston \\ Author Note
}

Aldert Vrij, Sharon Leal, Samantha Mann and Gary Dalton, Department of

Psychology, University of Portsmouth; Ronald P. Fisher, Department of Psychology, Florida International University; Eunkyung Jo, Department of Psychology, Hallym University; Allla Shaboltas, Maria Ivanova, Juliana Granskaya, Department of Psychology, St. Petersburg State University; Kate Houston, Department of Public Affairs and Social Research, Texas A\&M International University.

This article has been accepted for publication and undergone full peer review but has not been through the copyediting, typesetting, pagination and proofreading process which may lead to differences between this version and the Version of Record. Please cite this article as doi: $10.1002 /$ acp.3566 
Correspondence concerning this article should be addressed to Aldert Vrij,

Department of Psychology, University of Portsmouth, King Henry Building, King Henry 1

Street, PO1 2DY, Hants, United Kingdom. Email: aldert.vrij@port.ac.uk

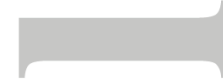

\section{Abstract}

Since interviewees typically say less when an interpreter is present, we examined whether this was caused by interpreters not interpreting everything interviewees says or by interviewees providing less information. We further examined (1) the effect of a model drawing on providing information and (2) the diagnostic value of total details and the proportion of complications as cues to deceit.

Hispanic, Russian, and South Korean participants were interviewed by native interviewers or by a British interviewer through an interpreter. Truth tellers discussed a trip they had made; liars fabricated a story. Participants received no instruction (condition 1) or were instructed to sketch while narrating without (condition 2) or with (condition 3) being given examples of detailed sketches.

Interviewees said less when an interpreter was present because they provided less information. Truth tellers gave more details and, particularly, obtained a higher proportion of complications than liars. The Sketching manipulation had no effect.

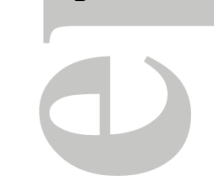

Keywords: interpreter, non-native speakers, information gathering, deception, drawings

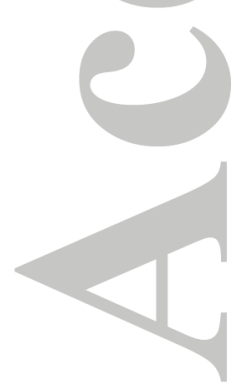




\section{Eliciting Information and Cues to Deceit through Sketching in}

\section{Interpreter-Based Interviews}

Interpreters are often introduced to resolve language barriers when interviewers and interviewees do not speak each other's language (Russano, Narchet, \& Kleinman, 2014: Russano, Narchet, Kleinman, \& Meissner, 2014). Although interpreters have been used frequently and for many years, experimental research examining the effect of an interpreter on rapport, the elicitation of information and cues to deceit only started to emerge recently (Ewens 2016a, b, 2017; Houston, Russano, \& Ricks, 2017; Vrij, Leal et al., 2017; Vrij et al., 2018a, c). In the current experiment, we also focused on the elicitation of information and cues to deceit, particularly (1) on reasons why interviewees may say less in interpreterpresent interviews than in interpreter-absent interviews, (2) how the introduction of a model drawing may encourage interviewees to say more and (3) how the presence of an interpreter and model drawing may affect truth tellers and liars differently.

\section{The effect of an interpreter on the information provided}

In a previous interpreter experiment, interviewees from Russian, Korean and Hispanic origin were interviewed in their own language by either a native interviewer or by an English interviewer through an interpreter (Vrij, Leal et al., 2017). The interviewees provided fewer details (defined as units of information) in the interpreter-present interviews than in the interpreter-absent interviews. Ewens et al. (2017) offered three explanations for this finding. First, perhaps information got lost in translation and the interpreter did not translate every detail the interviewee reported. Second, perhaps the frequent interruptions by the interpreter when translating the interviewee's recall distracted the interviewee, which subsequently impaired his/her memory (Nelson \& Goodmon, 2003). Third, the interviewee may have decided to be more concise when the interpreter was present, considering the time it takes for the interpreter to translate every detail. 
Vrij, Leal et al.’s (2017) study did not allow to empirically test Ewens et al.'s (2017) explanations, but in the present experiment we attempted such an empirical test. In the interpreter-present interviews, we did not only code the details in the interpreter's translation -as Vrij, Leal et al. (2017) did- but we also coded the details the interviewees actually reported. When comparing the interpreter's translation with the interviewee's recall we could thus examine how much information was lost in translation. We also examined the extent to which interviewees chose not to be detailed. We invited them in the interview to discuss as many 'key moments' as they would like, events of particular interest to them. To help them with this, we invited them first to write down as many key words as they would like, words that captured the event well. We counted the number of key words they wrote down and the number of key moments (key events) they reported. If interviewees chose to be concise in interpreter-present interviews, they would write down fewer key words and would describe fewer key events.

\section{The effect of veracity on the information provided}

Truth tellers typically report more details than liars (Amado, Arce, Fariña, \& Vilarino, 2016; DePaulo et al., 2003; Oberlader et al., 2016). Liars may be unable to report many details, given that these details should sound plausible (Köhnken, 2004), or may be unwilling to report many details, because they fear that such details may give leads to investigators that they are lying (Nahari, Vrij, \& Fisher, 2014). Researchers recently pointed out a limitation associated with relying on number of details when attempting to detect deceit (Vrij, Leal et al., 2017; Vrij et al., 2018a, b, c). Number of details is a general measure that does not take well enough into account the different strategies truth tellers and liars employ. Perhaps a measure that captures those strategies better will yield better results in terms of truth/lie detection. 
In search of measures that take the strategies truth tellers and liars use better into account, researchers recently started to examine specific types of detail: Complications, common knowledge details and self-handicapping strategies (Vrij, Leal et al., 2017; Vrij et al., 2018a, b, c). A complication is an occurrence that makes a situation more difficult to report than necessary (e.g., "On my way back I got lost and could not find the entry to the tube station"). Truth tellers are thought to report more complications than liars, due to liar's tendency to keep their stories simple (Hartwig, Granhag, \& Strömwall, 2007). Common knowledge details refer to strongly invoked stereotypical information about events (e.g., "We went to the top of the Eiffel Tower from where we had a wonderful view of Paris"). Liars are thought to report more common knowledge details than truth tellers, because liars lack personal experiences to add to their descriptions of events. Truth tellers have personal experiences of an event and are likely to report them when describing these events (DePaulo, Kashy, Kirkendol, Wyer, \& Epstein, 1996). Adding personal experiences when describing an event makes those descriptions less scripted. Self-handicapping strategies refer to justifications as to why someone is not able to provide information ("I can't tell you about the beginning of the BBQ, because I arrived late"). Liars are thought to report more self-handicapping strategies than truth tellers. Liars are inclined to keep stories simple, but are also concerned that just admitting lack of knowledge and/or memory appears suspicious (Ruby \& Brigham, 1998). A potential solution is to provide a justification for the inability to provide information.

If truth tellers are more likely to report one type of detail (complications) and liars other types of detail (common knowledge details and self-handicapping strategies), analysing the data separately for the three types of detail should be more informative about deception than analyzing the total number of details, which includes three types of detail. In particular, a proportion score, such as the proportion of cues to truthfulness -complications / 
(complications + common knowledge details + self-handicapping strategies)- should be more diagnostic than the total details variable. This was indeed found in the previous experiments (Vrij, Leal et al., 2017; Vrij et al., 2018a, b, c).

\section{The effect of a model statement drawing on the information provided}

Many practitioners told us that they use drawings as an information-gathering tool in interviews with suspects or sources. They also mentioned that they would be keen to learn whether drawings can be used as a lie detection tool. There are reasons to believe and evidence available that this might be the case, which is why we examined the use of drawings in this experiment. Since practitioners use tools in different settings, including in interviews with or without an interpreter present, it is important to examine the utility of a tool in such different settings, which we did in the present experiment.

Sketching while narrating facilitates recall in truth tellers (Dando, Wilcock, \& Milne, 2009; Leins, Fisher, Pludwinsky, Robertson, \& Mueller, 2014; Mattison, Dando, \& Omerod, 2015). Vrij et al. (2018a) provided four reasons why sketching facilitated recall in truth tellers. First, sketching mentally reinstates the context of the interviewee's experience and context reinstatement enhances recall. Second, sketching is a visual output and therefore more compatible with visually experienced events than just a verbal account. A more compatible output enhances recall. Third, sketching is a time-consuming activity which gives truth tellers good opportunity to search their memory. More time to retrieve an event could facilitate recall. Fourth, sketching automatically leads to the provision of spatial information as someone must situate each person or object somewhere in the location s/he sketches. In a verbal response someone not always spontaneously report where persons and objects were exactly located. 
As mentioned above, liars are typically unable or unwilling to report many details. Therefore methods that facilitate recall (such as sketching) should have a stronger effect on truth tellers than on liars, enhancing the difference in reporting details between them. This was indeed found in Vrij et al. (2018a). In their experiment, truth tellers and liars reported alleged activities. In the sketch condition, participants sketched while discussing these activities, whereas in the control condition, participants discussed these activities without sketching. Truth tellers provided more details and more complications than liars, but only in the sketch condition.

In the present experiment we sought to replicate Vrij et al.’s (2018a) findings but added a second drawing condition to the design: the model-drawing. In this condition participants were shown three examples of detailed drawings when asked to sketch while talking. Perhaps the amount of detail in these drawings would stimulate truth tellers to think about their experienced event in a similarly detailed manner which could subsequently enhance the number of details they would report. This would further enhance the differences between truth tellers and liars.

The principle behind the model drawing is thus somewhat similar to the principle behind the auditory model statement, which is an audiotaped example of a detail answer about a topic unrelated to the topic of investigation (Leal, Vrij, Warmelink, Vernham, \& Fisher, 2015). A model statement raises interviewees' expectations about how many details are desired (Ewens et al., 2016b) and research has shown that interviewees reported more details in model statement present interviews than in model statement absent interviews. (See Vrij, Leal, and Fisher [2018] for a review of these studies.) Exposure to a model statement resulted in truth tellers and liars reporting a similar amount of additional detail (Vrij, Leal, \& Fisher, 2018). Since a model statement makes it obvious to both truth tellers and liars that more detail is required (Ewens et al., 2016b), they apparently responded to a model statement 
in the same way. Most auditory model statement studies just examined the total number of details that was reported, but when a distinction was made in the type of detail they provided, a difference emerged: Truth tellers reported more complications than liars (Vrij, Leal et al., 2017). Truth tellers often do not report complications they have experienced because they are typically not crucial to understand the main message they wish to convey. Perhaps, only when they realise that they have to report many details, do they decide to report complications.

\section{Hypotheses}

The following hypotheses were tested:

Interviewees will describe fewer key moments (events of particular interest to them) and will write down fewer key words (words that capture these event well) in interpreter-present interviews than in interpreter-absent interviews (Hypothesis 1).

- Interviewees will report fewer details (defined as units of informartion) in interpreterpresent interviews than in interpreter-absent interviews (Hypothesis 2)

- Truth tellers will report more details and more complications than liars (Hypothesis 3a), whereas liars will report more common knowledge details and more self-handicapping strategies than truth tellers (Hypothesis $3 b$ )

- The proportion of complications will be higher in truth tellers than in liars (Hypothesis 4a) and will be a more diagnostic indicator of deceit than total details (Hypothesis $4 \mathrm{~b}$ )

- A model drawing will result in more details and more complications than a standard drawing, which, in turn, will result in more details and more complications than a no drawing control condition (Hypothesis 5)

- The effect presented in Hypothesis 5 will occur particularly in truth tellers (Hypothesis 6). We explored the effect of an interpreter on complications, common knowledge and self-handicapping strategies, because previous findings were inconsistent and difficult to 
explain. For example, if interviewees are more inclined to be concise in the presence of an interpreter, this could result in reporting fewer complications and more common knowledge details. However, this has not been found to date. Vrij, Leal et al. (2017) found no effect of an interpreter on complications, common knowledge and self-handicapping strategies, whereas Vrij et al. (2018c) found that interpreter-present interviews resulted in fewer common knowledge details than interpreter-absent interviews. They speculated that the presence of an interpreter gave interviewees more thinking time, which they used to make their stories sound less scripted.

\section{Participants}

\section{Method}

A total of 205 University students (39 males and 166 females) took part in the study. Their age ranged from $18-42$ years with an average age of $M=21.93$ years $(S D=3.87)$. The experiment took place in three different universities in South Korea, Russia and USA, and the participants were of Korean $(n=80)$, Russian $(n=80)$ and Hispanic $(n=45)$ origin.

\section{Procedure}

\section{Recruitment, pre-condition selection form, preparation and pre-interview} questionnaire.

We used the same procedure as Vrij, Leal et al. (2017) and Vrij et al. (2018a, c).

Participants were recruited via an advert on the university intranets and advertisement leaflets distributed in university buildings. The advert explained that the experiment would require participants to tell the truth or lie about a trip away that they may (or may not) have taken within the last year. We decided upon "within the last year" so that truth tellers would still remember many details about their trip and liars could not easily feign memory loss when answering the questions. Participants first received a participant information sheet and signed an informed consent form. They then completed a selection form that contained six cities that 
the researchers thought the participants may have visited during the past year. (Different cities were used for the three different countries.) The six cities were included on the selection form so that we would obtain some kind of standardization of the cities discussed in the study. The participants were also asked to write down the names of two other cities they had visited during the past year. We did so because if truth tellers had not been to any of the six cities mentioned on the selection form in the past twelve months, they could discuss in the interview one of these two additional cities.

For each city the participants indicated (a) whether they had been there during the last twelve months, (b) when they had been there during the last twelve months, (c) for how long they stayed there, and (d) whether they have lived there. For truth tellers, the experimenter selected one of the six cities where the participant had stayed during the last twelve months for at least two nights but had never lived there. In case a truth teller had stayed in only one of those six cities, that particularly city was chosen. In case a truth teller had stayed in more than one of these six cities the experimenter chose a city, ideally one that had not been discussed by (too) many truth tellers before so that we would obtain a variety of cities being discussed. In case a truth teller had not been to any of the six cities, the experimenter selected one of the additional cities that the truth teller had listed on the selection form. Truth tellers were informed that they would be interviewed about this selected city (city X) and asked to answer the questions truthfully. For liars, the experimenter selected either one of the six cities on the selection form where the liar had never been in his/her life before, or selected a city not on the list but which was discussed by a truth teller during an interview (after checking that the liar had never been to this city before). In other words, the truth tellers' and liars' cities were matched. Liars were informed that they would be interviewed about city X and that they had to pretend to have stayed there for at least two nights during a trip made during the last twelve months. Across all 102 truth tellers, more than 60 cities were used. Each truth 
teller reported a trip to a single city (rather than to multiple cities). The cities liars discussed were taken from this sample of 60 cities.

Participants were then given a computer with internet access and told they had twenty minutes to prepare themselves for their interview, or to inform the experimenter if they were ready before that time. The participants were told that they were allowed to make notes while doing their research. They were also told that it was important to be convincing because, if they did not appear convincing, they would be asked to write a statement about what they told the interviewer in the interview. In a pre-interview questionnaire the truth tellers and liars rated their thoroughness of preparation via three items: (1) shallow to (7) thorough; (1) insufficient to (7) sufficient; and (1) poor to (7) good. The answers to the three questions were averaged (Cronbach's alpha $=.84$ ) and the variable is called 'preparation thoroughness'. They were also asked whether they thought they were given enough time to prepare themselves with the following question: 'Do you think the amount of time you were given to prepare was: (1) insufficient to (7) sufficient. Finally, they were asked how motivated they were to perform well during the interview: (1) not at all motivated to (5) very motivated.

\section{Experimental conditions.}

Participants were allocated randomly to one of the twelve experimental cells. A total of 102 participants were allocated to the truth condition and 103 to the lie condition; 69 to the Sketching-absent condition, 68 to the Sketching-present condition and 68 to the Model Sketching-present condition; 101 to the Interpreter-absent condition and 104 to the Interpreter-present condition. Individual cell sizes varied from 16 to 18 . These cell sizes are rather small, making it difficult to detect the 2 X 2 X 3 interaction; the cell sizes are adequate, though, for the various main effects and 2-way interactions (cell sizes for all two-way interactions and main effects were $>34$ ). 
In total, three interpreters were used in the study, one in each country. The Korean and Russian interpreters were the same as used in Vrij, Leal et al. (2017) and Vrij et al. $(2018 \mathrm{a}, \mathrm{c})$. The Korean interpreter was a professional interpreter and the Russian interpreter spoke fluent English. The Hispanic interpreter was English - Hispanic bilingual. The interpreters were instructed to use a long consecutive interpreter style (Viezzi, 2012). In this interpreter style, the interviewee provides chunks of information at a time with the interpreter writing down what the interviewee says. During a natural pause in the interviewee's speech, the interpreter interprets the chunk of information consulting his/her notes.

In the interpreter condition, one British interviewer was used, and in the noninterpreter condition one Russian, one Korean and one Hispanic interviewer were used. The British and Russian interviewers were the same as in Vrij, Leal et al. (2017) and Vrij et al. (2018a, c), whereas the Korean and Hispanic interviewers were new. Prior to the experiment the British interviewer -a very experienced interviewer and has interviewed in many experiments before- instructed the other interviewers how to conduct the interview. They were instructed to be friendly and not to interrupt the interviewee. Practice sessions took place until the British interviewer was satisfied with the interview style of each interviewer. That is, she was satisfied with the demeanour of the interviewers (appeared friendly) and the opportunities they gave to the interviewees to talk (no interruptions). To assess consistency in interview style between the interpreter and non-interpreter conditions, participants were asked to assess in a post-questionnaire the rapport they experienced with the interviewer (see below). All interpreters and interviewers were blind to the veracity condition.

Nationality is confounded with the specific interviewer and specific interpreter. To control for the possible effects of this confound, we included site as a covariate in the hypotheses-testing analyses. 


\section{The interview.}

Prior to the interview, the experimenter told the interviewer about which city to interview the participant. To make the interviewee feel comfortable and to avoid floor effects in establishing rapport interviewees were offered a glass of water from the interviewer, as offering something helps rapport building (reciprocation principle, Cialdini, 2007).

The interviewer started by saying "I will interview you about your trip to

Depending on your answers, we may decide to interview you a second time." This was followed by the following request: "Please tell me in as much detail as possible everything you did when you were at from the moment you arrived to the moment you left."

We label this initial request and answer, Phase 1.

After the interviewee's answer, Phase 2 started with the following request: "I want you now to think about key moments or memorable events during your trip. Take a few moments to picture in your mind such key moments or memorable events. Now think about where you were and what you saw at that time, including who you were with, descriptions of objects and locations, and the sequence of actions. Write down some key words that summarise your experiences and please let me know when you have done this". After this request, the interviewer asked the interviewee to report one key moment and then introduced the sketching manipulation: In the Sketching-absent condition the interviewer said: "Now please tell me everything you remember". In the Standard-Sketching condition the interyiewer said: "Now please tell me everything you remember but while doing this make a sketch of what you could see". In the Model-Sketching condition the interviewer said: "Now please tell me everything you remember but while doing this make a sketch of what you could see. Before you start have a look at these three sketches made by someone who described her experience at the dentist". We then showed the participants three detailed sketches of a dentist visit: One sketch of the building from the outside; one sketch from the 
waiting room; and one sketch from the dentist room. We left the sketches next to the participants while they talked and sketched. We chose the dentist as a topic because we wanted to avoid showing participants pictures of an experience they were about to describe themselves. We thought it unlikely for them to describe a visit to the dentist and nobody actually did.

The participants in the Standard-Sketching and Model-Sketching conditions were given sheets of A4-sized paper and a set of coloured pencils to make the sketch. They were also reassured that the quality of their drawing did not matter. While the interviewees sketched and talked the interpreter took notes of what the interviewees said and conveyed this information to the interviewer at regular times, during which the interviewees stayed quiet. We label the verbal recall of the participants to this request is called Phase 2, event 1.

After the participants finished their description of the first event, they were invited to

describe another event if they wished. Those in the sketching conditions were requested to sketch and talk again. The interview was finished when (1) interviewees said that they had no further event to report, or (2) after they reported four events. We label this Phase 2, events 24.

A total of 184 participants described more than one event. The 21 participants who only described one event included 14 truth tellers and 7 liars; 14 participants from the interpreter-present interviews and 7 from the interpreter-absent interviews; and 11 from the Model-Sketching condition, 5 from the Standard-Sketching condition and 5 from the Sketching-absent condition. In sum, 205 participants produced verbal reports in Phase 1 and Phase 2, event 1 and 184 participants produced verbal reports in Phase 2, events 2-4. The interviews were video (interviewees only) and audio recorded. The Russian, Korean and Hispanic speech was transcribed and then translated into English. For the interpreter-present interviews this resulted in two segments of English text: The original 
speech from the interviewee translated into English and the English speech from the interpreter as she interpreted the interviewee's speech during the interview. In the main analyses we used the English speech spoken by the interpreter (interpreter-text). We did this because it is this speech that interviewers will understand in real-life interviews with interpreters. In the follow-up part of the study (see the Results section) we also used the original speech by the interviewee translated into English (interviewee-text) and compared the interpreter-text with the interviewee-text.

\section{Post-interview questionnaire.}

After the interview, participants completed a post-interview questionnaire, which was written in the participant's native language. The participants were asked to indicate the extent to which they told the truth during the interview on an 11 point Likert scale ranging from $0 \%$ to $100 \%$.

Rapport was measured via the nine-item Interaction Questionnaire (Vallano \& Schreiber Compo, 2011). Participants rated the interviewer on 7-point scales ranging from [1] not at all to [7] extremely on nine characteristics such as smooth, bored, engrossed, and involved (Cronbach's alpha $=.84)$.

For those participants who were asked to sketch we asked about their experiences.

They were asked the following four questions, which they answered on 7-point scales ranging from (1) not at all to (7) very much so: (a) 'Sketching while narrating was easy to do', (b) 'Sketching while narrating was difficult to do', (c) 'Sketching while narrating made it easier for me to think what I wanted to say', (d) 'Sketching while narrating made it more difficult for me to think what I wanted to say'. Questions (b) and (d) were recoded and the four questions were averaged to form the cluster labeled "easy to sketch and talk" (Cronbach's alpha $=.84)$. 


\section{Coding}

\section{Detail.}

The coders, blind to the Veracity condition, were taught the coding scheme by the first author who has more than twenty years of experience in coding detail. A coder first read the transcripts and coded each detail in the interview. A detail is defined as a unit of information about the trip the interviewee allegedly had made. For example, the following answer has seven details: "I'm also drawing a plaza that is in front of the cathedral. There was a large fountain. It had a lot of seats, or benches". Each detail in the interview was coded only once; thus repetitions were not coded. A second coder coded a random sample of 40 transcripts. Inter-rater reliability between the two coders, using the two-way random effects model measuring consistency, was good (Single Measures ICC $=.74)$.

Two coders coded independently from each other the following measures in all transcripts: Complications, common knowledge details and self-handicapping strategies. Repetitions were not coded. A complication is an occurrence that makes a situation more difficult to report than necessary (Vrij et al., 2018b). Example of complications are (a) "We wanted to go to the theatre, but it was closed"; (b) "I fell and my bike got stuck in a tree"; and (c) "The hotel beach was full of little stones". Common knowledge details refer to strongly invoked stereotypical knowledge about events (Vrij et al., 2018b). Examples of common knowledge details are: (d) "We also managed to visit the Olympic Park", (e) "We also visited a car museum with different Soviet cars" and (f) "We walked in the city and looked at the old buildings". Self-handicapping strategies refer to explicit or implicit justifications as to why someone is not able to provide information (Vrij et al., 2018b). Examples of selfhandicapping strategies are: (g) "We decided not to go inside because we already saw such a fortress before", (h) "I can't remember the name of the hotel, I don't speak Swedish" and (i) "I'm not very good at remembering names, so I will just tell you common details". 
Inter-rater reliability between the two coders, using the two-way random effects model measuring consistency, was good for complications (Average Measures, Intraclass correlation coefficient, ICC $=.92$ ) and common knowledge details (Average Measures ICC $=$ .78 ) and satisfactory for self-handicapping strategies (Average Measures ICC $=.68$ ).

Disagreements were resolved between the two coders.

The key words the participants had written down when thinking about memorable events were translated into English and the number of key words written down were entered into the SPSS file. The details coder also counted how many events were described.

\section{Results}

All statistical information for the Veracity main effect appear in Table 1 and for the Interpreter main effect in Table 2. For the dependent variables presented in the Hypothesestesting part of this Results section, we report the statistical information regardless of whether the Veracity or Interpreter main effect was significant. For the remaining dependent variables, presented before the Hypotheses-testing part, we only report the significant results. We do not report the Sketch main effect results in a table due to a lack of significant results (only one significant Sketch univariate main effect emerged, for proportion of complications in Phase 2, Event $1, F(2,187)=3.51, p=.032, \eta_{p}{ }^{2}=.036$, all other $F^{\prime} s<2.35$, all $p$ 's $>$ $.099)$.

\section{Preparation thoroughness, preparation time and motivation}

Three 2 (Veracity) X 3 (Sketch) X 2 (Interpreter) ANOVAs were carried out with preparation thoroughness, preparation time and motivation as dependent variables. For preparation thoroughness, a significant main effect for Veracity emerged: Truth tellers rated their preparation as more thorough than liars (Table 1). All other effects were not significant, all $F$ 's $<2.25$, all $p$ 's $>.134$. For interview time, also as significant main effect emerged: Truth tellers believed more than liars that they were given sufficient time to prepare 
themselves for the interview (Table 1). All other effects were not significant, all $F$ ' $s<1.85$, all $p$ 's $>.176$. For motivation, although random allocation to the Interpreter condition took place after the participants completed the pre-interview questionnaire, a significant main effect for Interpreter emerged. Participants were more motivated in the interpreter-present than in the interpreter-absent interviews (Table 2). All other effects were not significant, all $F$ 's $<1.01$, all $p$ 's $>.367$. Since preparation thoroughness, preparation time and motivation may affect participants' verbal output, we introduced these variables as covariates in the analyses where we examined verbal output.

Note that preparation thoroughness and preparation time were measured on 7-point Likert scales but motivation on a 5-point Likert scale. The means for preparation thoroughness were $M=4.67(S D=1.18)$ for truth tellers and $M=4.30(S D=1.17)$ for liars, suggesting that both truth tellers and liars found their preparation thoroughness moderate. The mean scores for preparation time were $M=6.07(S D=1.13)$ for truth tellers and $M=$ $5.35(S D=1.72)$ for liars, indicating that both truth tellers and liars thought they were given sufficient time to prepare themselves. The grand mean for motivation was $M=4.00(S D=$ 0.71) which means that participants were very motivated.

Insert Tables 1 and 2 about here

\section{Easy to sketch while talking}

A 2 (Veracity) X 3 (Sketch) X 2 (Interpreter) ANOVA with easy to sketch while talking as dependent variable revealed a Veracity $\mathrm{X}$ Interpreter interaction effect, $F(1,128)=$ 3.99, $p=.048, \eta_{p}{ }^{2}=0.03$. All other effects were not significant, all $F$ ' $s<2.28$, all $p$ 's $>.133$. Simple effect tests showed that the interpreter had no effect on truth tellers, $F(1,66)=0.23, p$ $=.631, d=.12(-.36, .59)$, but for liars, sketching while narrating was more difficult with $(M=$ $2.75, S D=1.52,95 \% C I[2.26,3.24])$ than without $(M=3.66, S D=1.31,95 \% C I[3.17$, 4.14]) an interpreter present, $F(1,66)=6.93, p=.011, d=.64(.14,1.12)$. 


\section{Rapport and percentage of truth telling}

Two ANOVAs utilizing a 2 (Veracity) X 3 (Sketch) X 2 (Interpreter) between-

subjects design were carried out with (1) rapport, and (2) percentage of truth telling as dependent variables. The analysis with Rapport resulted in one significant effect, an Interpreter main effect: Rapport was better with the interpreter present than with the interpreter absent (Table 2). All other effects were not significant, all $F$ 's $\langle 2.67$, all $p$ 's $>$ .071 . We included Rapport as a covariate in the analyses when we examined verbal output.

For percentage of truth telling, a main effect for Veracity occurred: Truth tellers reported to have been more truthful than liars. The Veracity X Interpreter interaction effect was also significant, $F(1,202)=4.32, p=.039, \eta_{p}{ }^{2}=.02$. Simple effect tests showed no significant difference between the interpreter-absent and interpreter-present conditions for truth tellers, $F(1,100)=1.14, p<.288, d=.21(-.18, .60)$ or for liars, $F(1,101)=3.24, p=$ $.075, d=.35(-.04, .74)$. All other effects were not significant, all $F$ 's $<1.36$, all $p$ 's $>.246$,

\section{Time since the trip was made}

Truth tellers were asked on the pre-condition selection form to indicate when they made the trip they discussed. On average this trip was made $M=5.41$ months prior to the interview $(S D=2.81)$. This variable was not correlated with any of the main dependent variables in the study (detail, complications, common knowledge details, self-handicapping strategies or ratio of complications), all $r$ 's $<.17$, all $p$ 's $>.103$ ).

\section{Hypothesis Testing}

\section{Number of key events written down.}

An ANCOVA utilizing a 2 (Veracity) X 2 (Interpreter) between-subjects design was carried out with the number of key words written down as the dependent variable.

Preparation thoroughness, preparation time, motivation, rapport and site were the covariates. Since the Sketch manipulation was introduced after the participants had written down their 
key moments, the Sketch factor was not included in this analysis. The analysis resulted in an Interpreter main effect: Participants wrote down more key moments when the interpreter was present than when the interpreter was absent (Table 2), rejecting Hypothesis 1. The remaining effects were not significant, both $F$ 's $<0.25$, both $p$ 's $>.619$.

\section{Number of events reported.}

An ANCOVA utilizing a 2 (Veracity) X 3 (Sketch) X 2 (Interpreter) between-subjects design was carried out with the number of events written down as the dependent variable.

Preparation thoroughness, preparation time, motivation, rapport and site were the covariates. The analysis revealed one effect, a main Interpreter effect: Participants described more events without an interpreter than with an interpreter (Table 2), supporting Hypothesis 1. All other effects were not significant, all $F$ 's $<2.80$, all $p$ 's $>063$.

\section{Phase 1 ( $\mathbf{N}$ = 205): Initial narrative.}

A MANCOVA utilizing a 2 (Veracity) X 2 (Interpreter) between-subjects design was carried out with total details, complications, common knowledge details, and selfhandicapping strategies as well as proportion of complications reported in Phase 1 as the dependent variables. Preparation thoroughness, preparation time, motivation, rapport and site were covariates. Since the Sketch manipulation was introduced after Phase 1, the Sketch factor was not included in this analysis.

At a multivariate level, the analysis revealed main effects for Veracity $F(5,192)=$ $6.84, p<.001, \eta_{p}{ }^{2}=.15$ and Interpreter $F(5,192)=2.30, p=.047, \eta_{p}{ }^{2}=.06$, whereas the Veracity x Interpreter interaction effect $F(5,192)=1.79, p=.117, \eta_{p}{ }^{2}=.04$, was not significant. The univariate main effects for Veracity are presented in Table 1. Truth tellers provided more details and complications than liars, and fewer common knowledge details and self-handicapping strategies than liars. This supports Hypotheses $3 \mathrm{a}$ and $3 \mathrm{~b}$ for Phase 1.The proportion of complications was higher in truth teller than in liars. Although Veracity 
was a significant predictor for all of the dependent measures, the effect size for total details was the smallest $(d=.23)$ and considerably smaller than those for complications $(d=.68)$ and proportion of complications $(d=.68)$. This supports Hypotheses $4 \mathrm{a}$ and $4 \mathrm{~b}$ for Phase 1.

The Interpreter univariate main effects are presented in Table 2. In interpreter-present interviews fewer details and complications were reported than in interpreter-absent interviews. This supports Hypothesis 2 for Phase 1.

\section{Phase 2, Event $1(\mathrm{~N}=205)$ : Key moment 1 description.}

A MANCOVA utilizing a 2 (Veracity) X 3 (Sketch) X 2 (Interpreter) betweensubjects design was carried out with total details, complications, common knowledge details, and self-handicapping strategies as well as proportion of complications reported in Phase 2,

Event 1 as the dependent variables. Note that we only coded the new details, new complications etc., which were not reported by the participants in Phase 1 . Since the occurrence of those could depend on what was reported in Phase 1, we also included total details at Phase 1 as a covariate. As a result, preparation thoroughness, preparation time, motivation, rapport, site and total details reported at Phase 1 were the covariates. At a multivariate level, the analysis revealed a significant Veracity main effect, $F(5,183)=5.43, p$ $<.001, \eta_{p}{ }^{2}=.12$, and a significant Veracity $\mathrm{x}$ Sketch $\mathrm{x}$ Interpreter interaction effect, $F(5,183)$ $=2.34, p=.011, \eta_{p}{ }^{2}=.06$. However, at a univariate level none of the 3-way interaction effects were significant, all $F$ 's $<2.62$, all $p$ 's $>.075$.

The univariate main effects for Veracity are presented in Table 1. The findings are similar to those found for Phase 1, with the exception that the effect for self-handicapping strategies was no longer significant. Apart from this, again, truth tellers provided more details and complications than liars (supporting Hypothesis 3a), and fewer common knowledge details than liars (partially supporting Hypothesis 3b). The proportion of complications was also higher in truth teller than in liars (supporting Hypothesis 4a) and the effect size was 
again smaller for total details $(d=.38)$ than for proportion of complications $(d=.62)$, supporting Hypothesis $4 \mathrm{~b}$.

All other multivariate effects were not significant, all $F$ 's $<1.95$, all $p$ 's $>.088$. Hypotheses 5 and 6 are therefore rejected. Despite the absence of a multivariate main Interpreter main effect, $F(5,183)=1.94, p<.089, \eta_{p}{ }^{2}=.05$, Table 2 shows that in interpreter-present interviews fewer complications were reported than in interpreter-absent interviews. Since total details was not significant, Hypothesis 2 is rejected for Phase 2, Event 1.

Phase 2, Events 2-4 ( $\mathrm{N}=184)$ : Key moments 2-4 descriptions.

A MANCOVA utilizing a 2 (Veracity) X 3 (Sketch) X 2 (Interpreter) betweensubjects design was carried out with the new total details, complications, common knowledge details, and self-handicapping strategies as well as Proportion of complications reported in Phase 2, Events 2-4 as dependent variables. Note that we coded only the new details, new complications etc., which have not been reported by the participants in Phase 1. Preparation thoroughness, preparation time, motivation, rapport, site and total details at Phase 1 were the covariates. Since the events participants reported in Phase 2 differed from each other, there was never an overlap in reported details between Phase 2, Event 1 and Phase 2, Events 2-4. At a multivariate level, the analysis revealed a significant main effect for Veracity $F(5,162)=8.13, p<.001, \eta_{p}{ }^{2}=.20$. The univariate main effects for Veracity are presented in Table 1. Truth tellers provided more details and complications than liars, and fewer common knowledge details and self-handicapping strategies than liars. The proportion of complications was higher in truth teller than in liars. The effect sizes were the smallest for self-handicapping strategies $(d=.26)$ and total details $(d=.46)$ and the highest for proportion of complications $(d=.92)$. This supports Hypotheses $3 \mathrm{a}, 3 \mathrm{~b}, 4 \mathrm{a}$ and $4 \mathrm{~b}$ for Phase 2 Events 24. 
The Veracity $\mathrm{X}$ Interpreter interaction effect was also significant, $F(5,162)=3.10, p$ $=.011, \eta_{p}^{2}=.09$. However, at a univariate level, none of the Veracity X Interpreter interaction effects were significant, all $F$ 's $<2.56$, all $p$ 's $>.111$.

All other effects were not significant, all $F$ 's $<1.76$, all $p$ 's $>.126$. Although the multivariate Interpreter main effect was not significant, $F(5,162)=1.75, p=.127, \eta_{p}^{2}=.05$, the univariate effects again showed that interpreter-present interviews resulted in fewer details than interpreter-absent interviews, see Table 2. This supports Hypothesis 2. Since the Sketch factor did not yield a significant result, Hypotheses 5 and 6 were again rejected.

\section{Interpreter-text versus Interviewee-text Comparisons}

In this section we compare the interpreter's text and interviewee's text in three different ways. First, we compared these two types of text in a within-subjects comparison.

We focused hereby on the total unique details, complications, common knowledge details and self-handicapping strategies reported during the entire interview. We thus ignored the different phases. We also analysed the results for the proportion of complications and for a new variable: The total number of words spoken by the interpreter or interviewee. The results are presented in Table 3.

In the second analysis we compared the interpreter absent and interpreter's text results for the dependent variables listed in the previous paragraph. We also included Veracity as a factor but left out the Sketch factor. The dependent variables are not suitable for an analysis including the Sketch factor because it includes Phase 1 data in which sketching was not manipulated. Since the Sketch factor had no effect on the data, we do not consider leaving out this factor problematic. The third analysis was similar to the second analysis, except that we now use the interviewee-text data instead of the interpreter-text data. 


\section{Analysis 1: Within-subjects comparison}

A within-subjects analysis with Text (interpreter vs interviewee) as the only factor and total unique details, complications, common knowledge details, and self-handicapping strategies as well as proportion of complications and word count as the dependent variables revealed a significant multivariate effect, $F(6,98)=8.38, p<.001, \eta_{p}{ }^{2}=.34$. The univariate effects are presented in Table 3.

Table 3 about here

The interviewee's text contained more words than the interpreter's text but not more unique details. The interviewee's text also contained more self-handicapping strategies than the interpreter's text, and the proportion of complications was lower in the interviewee's text than in the interpreter's text. No other significant effects occurred. Regarding the three significant findings, the effect size for word count was moderate $(d=.38)$, but the other two effect sizes were small ( $d=.19$ and $d=.10$ respectively). This suggests not much difference between the interpreter and interviewee texts.

\section{Analysis 2: Interpreter absent - interpreter's text comparison}

A MANCOVA was carried out utilizing a 2 (Veracity) X 2 (Interpreter: absent vs interpreter's text) between-subjects design with total unique details, complications, common knowledge details, and self-handicapping strategies as well as the proportion of complications and number of words as the dependent variables. Preparation thoroughness, preparation time, motivation, rapport and site were the covariates. At a multivariate level, the analysis revealed a significant main effects for Veracity $F(6,191)=12.10, p<.001, \eta_{p}{ }^{2}=.28$ and Interpreter $F(6,191)=3.33, p=.004, \eta_{p}{ }^{2}=.10$ and a significant Veracity $\mathrm{X}$ Interpreter interaction effect, $F(6,191)=2.41, p=.029, \eta_{p}{ }^{2}=.07$. 
The Veracity main effects are presented in the top half of Table 4. Except for number of words, all effects were significant. When the interpreter's text was considered, truth tellers reported more unique details and complications and fewer unique common knowledge details and self-handicapping strategies than liars. The proportion of complications was also higher for truth tellers than liars. The $d$-scores for complications $(d=.80)$ and proportion of complications $(d=.87)$ in particular were high and higher than those for total details $(d=$ .45). This again supports Hypotheses 3a, 3b, 4a and $4 b$.

The Interpreter main effects are presented in the bottom half of Table 4. When the interpreter's text was considered, the interpreter-absent interviews resulted in more words and unique details than the interpreter-present interviews. This supports Hypothesis 2. The interpreter-absent interviews also included more unique complications and more selfhandicapping strategies than the interpreter-present interviews. The other effects were not significant.

At a univariate level, only one Veracity x Interpreter interaction effect was significant, the effect for unique complications $F(1,196)=4.12, p=.044, \eta_{p}{ }^{2}=.02$. The effect is presented in Table 6. For truth tellers, the interpreter-absent interviews resulted in more unique complications than the interpreter-present interviews; by comparison, for liars, no difference emerged between the two conditions.

\section{Analysis 3: Interpreter absent - interviewee's text comparison}

For the third analysis, a MANCOVA utilizing a 2 (Veracity) X 2 (Interpreter: absent vs interviewee's text) between-subjects design was carried out with total unique details, complications, common knowledge details, and self-handicapping strategies as well as the proportion of complications and number of words as the dependent variables. Preparation thoroughness, preparation time, motivation, rapport and site were the covariates. At a multivariate level, the analysis revealed a significant main effects for Veracity $F(6,191)=$ 
$9.98, p<.001, \eta_{p}{ }^{2}=.24$ and Interpreter $F(6,191)=3.77, p=.001, \eta_{p}{ }^{2}=.11$. The Veracity $\mathrm{X}$ Interpreter interaction effect was marginally significant, $F(6,191)=2.12, p=.053, \eta_{p}{ }^{2}=.06$.

The Veracity main effects are presented in the top half of Table 5. The findings were very similar to what we found with the interpreter's text analysis. When the interviewee's text was considered, again, except for number of words, all effects were significant. Truth tellers reported more unique details and complications and fewer unique common knowledge details and self-handicapping strategies than liars. The proportion of complications was also higher for truth tellers. The d-scores for complications $(d=.73)$ and proportion of complications $(d=.77)$ in particular were high. The effect sizes in the analyses with the interviewee's text (Table 5) are very similar to those obtained with the interpreter's text (Table 4).

The Interpreter main effects are presented in the bottom half of Table 5. When the interviewee's text was considered, the interpreter-absent interviews resulted in more unique details and more unique complications than the interpreter-present interviews This supports Hypothesis 2. The other effects were not significant. The differences between this analysis and the analysis with the interpreter's text (Table 4) were that the effects for number of words and self-handicapping strategies were now no longer significant.

Although the Veracity x Interpreter multivariate interaction effect was not significant, at a univariate level the same effect emerged as in the analysis with the interpreter's text: A significant Veracity $\mathrm{x}$ Interpreter interaction effect for unique complications emerged, $F(1$, $196)=4.64, p=.032, \eta_{p}{ }^{2}=.02$. The effect followed the same pattern as for the interpreter's text analysis: For truth tellers, the interpreter-absent interviews resulted in more complications than the interpreter-present interviews, whereas for liars no difference between the two conditions emerged (Table 6). 


\section{Discussion}

\section{Interpreter effects}

The interpreter-absent interviews resulted in more details than the interpreter-present interviews. This effect was not caused by interpreters' lack of translating all details the interviewee reported: There was no difference in the reported details between the interviewee's text and interpreter's text, and interview-present interviews resulted in fewer details even when the analysis was of the interviewee's text. This does not mean that interpreters translated every word the interviewee said. They did not, as evidenced by the interviewee's text containing more words than the interpreter's text. However, in terms of translating details -defined by us as units of information- no information was lost.

Rather than information being lost in translation, interviewees reported fewer details in interpreter-present interviews than in interpreter-absent interviews. In the Introduction we gave two possible reasons for this: Perhaps the frequent interruptions by the interpreter when translating the interviewee's recall distracted the interviewee, which subsequently impaired his/her memory of the event; or perhaps the interviewee decided to be more concise when the interpreter was present, considering the time it takes for the interpreter to translate every detail. Our findings do not allow us to conclude the extent to which each of these two explanations contributed to the effect, but we found evidence that interviewees chose to be more concise: In the interpreter-present condition, interviewees reported fewer events than in the interpreter-absent condition. This happened despite that in the interpreter-present condition (1) interviewees wrote down more key words to discuss in the interview and (2) reported to have been more motivated than in the interpreter-absent interviews. The instruction to write down key words was vague: Interviewees were asked to write key words down without being told what to do with them. This may have contributed to the finding that interviewees wrote down more key words in the interpreter-present condition than in the 
interpreter-absent condition. Perhaps they thought they were asked to write them down to help the interpreter.

The finding that no information was lost in translation depends, of course, on the quality of the interpreters used and cannot be generalised to all interpreter-present interviews.

However, we believe that the finding that the presence of an interpreter encourages interviewees to report fewer details can be generalised to other interpreter-present interviews. In interviews where it is important to collect as much information as possible, we thus recommend to use interviewers who speak the interviewee's language rather than to use interpreters.

Interpreter-present interviews resulted in fewer complications than interpreter-absent interviews. This was found in both the interpreter's text and interviewee's text, meaning that interviewees actually reported fewer complications in interpreter-present interviews rather than the interpreter failing to translate them. Perhaps, interviewees were more inclined to be concise in the presence of an interpreter, which resulted in reporting fewer complications, because the main message can typically be conveyed without mentioning complications. However, in previous studies using the same deception scenario as the one used in the present experiment, no difference in reporting complications between interpreter-absent and interpreter-present interviews have been found (Vrij, Leal et al., 2017; Vrij et al., 2018c). Instead, Vrij et al. (2018c) found that interpreter-present interviews resulted in fewer common knowledge details than interpreter-absent interviews, a finding not replicated in the current study. In other words, to date no clear pattern has emerged how the presence of an interpreter influences the occurrence of complications and common knowledge details. We believe that this issue warrants further investigation given the importance of such cues for verbal lie detection purposes. 
In the current study the presence of an interpreter had an effect on self-handicapping strategies. This pattern differs from previous studies in which we found no effect of the interpreter on self-handicapping strategies (Vrij et al., 2017, 2018c). Self-handicapping strategies were reported less in interpreter-present interviews, which was caused by interpreters not translating all of them rather than interviewees generating fewer. Since a selfhandicapping strategy utterance explains why someone cannot provide certain information, interpreters perhaps focused on what they found more informative - the details interviewees did report- rather than focusing on what they found less informative: the reasons interviewees gave for not reporting details.

\section{Veracity effects}

Truth tellers reported more total details and more complications, but fewer common knowledge details and fewer self-handicapping strategies than liars. As a result, the proportion of complications was also higher in truth tellers than in liars, and this variable discriminated truth tellers from liars better than total details. These findings replicate what has been found in previous studies (Vrij 2017, 2018a, b, c). These findings should not be misunderstood. We are not arguing that total details is a poor indicator of deceit. Truth tellers typically report more details than liars as meta-analyses revealed (Amado et al., 2016;

DePaulo et al., 2003; Oberlader et al., 2016) and we also found this in the present experiment. However, we argue that the proportion of complications may be a more diagnostic cue to distinguish truth tellers from liars than total details. We therefore encourage researchers and practitioners to examine complications, common knowledge details, self-handicapping strategies and the proportion of complications. We realise that examining the proportion of complications could be challenging for practitioners, even more so when they are supposed to calculate this in real time during interviews. Note that just the variable complications also yielded strong Veracity effect, both in the current experiment and in previous experiments 
(Vrij, Leal et al. 2017; Vrij et al., 2018a, b, c). Practitioners may decide just to focus on complications instead.

\section{Sketching effects}

We found only one effect of sketching, a Veracity x Interpreter effect. Liars reported that they found sketching more difficult with than without an interpreter, whereas the presence of an interpreter had no effect on truth tellers. Whatever the reason for this, it did not affect liars' verbal responses when sketching. In fact, we failed to find any significant effects for the Sketch manipulation in terms of participants' responses. This went against our predictions and also contradicted previous research. In research with cooperative witnesses (truth tellers) it has been found that the instruction to sketch while narrating resulted in more information than the instruction just to talk (Dando, Wilcock, \& Milne, 2009; Leins, Fisher, Pludwinsky, Robertson, Mueller, 2014; Mattison, Dando, \& Ormerod, 2015). And in the only other deception study including sketching while narrating to date, it was found that truth tellers provided more details and complications than liars, but only in the sketch while narrating condition (Vrij et al., 2018a). A lack of power could not have explained the absence of the Veracity main or Veracity x Sketch interaction effects. There were at least 68 participants in each of the three cells that represented the Sketch factor and for the Veracity $\mathrm{x}$ Sketch interaction, there were at least 34 participants in each cell. Cell sizes of 68 and 34 are large enough to observe strong and medium effects respectively. G*Power a priori tests indicate that for MANOVA for special effects and interactions, with 3 groups, 2 predictors and measuring up to 6 response variables, a total sample size of 32 is required for an $\mathrm{f}^{2}(\mathrm{~V})=$ 0.5, and 23 for $\mathrm{f}^{2}(\mathrm{~V})=0.8$ (Faul, Erdfelder, Lang, \& Buchner, 2007).

We believe that the present null effects were caused by our procedural instruction that was unique to the present experiment. Specifically, we asked participants to write down key words about what they wanted to discuss in the interview--which did not happen in previous 
studies. We did so to examine whether the presence of an interpreter would affect how many key words participants would write down. We now believe that this instruction affected the drawing findings. Through this instruction, participants committed themselves to what to report prior to the Sketch manipulation and this may have overshadowed the effect of the Sketch manipulation itself. If our explanation is correct, then the timing and wording of the sketch instructions is important. When we discuss the use of sketches with practitioners they often tell us that they do not have a specific strategy of how and when to introduce the sketch request; neither do they contemplate whether this would matter. We hope that future research will examine the best way to introduce sketches in interview settings.

\section{Methodological considerations}

In Phase 2, interviewees could have used two different strategies. They could have chosen to discuss a few events in more detail or more events in less detail. Our data enable us to distinguish between these two strategies only indirectly, by considering (1) the number of events discussed as an indicator of how many events an interviewee chose to discuss and (2) the number of key words written down as the amount of detail s/he chose to report about an event. No Veracity effect emerged for these two variables. For the Interpreter factor significant differences emerged. In the Interpreter-present condition interviewees reported fewer events but wrote down more key words than in the Interpreter-absent condition.

Although the interview consisted of two phases, we did not include Phase as a withinfactor in the design for several reasons. First, the coding in the two phases was not independent from each other. We examined new information reported in Phase 2 not yet reported in Phase 1. The amount of new information in Phase 2 depends on the amount of information already reported in Phase 1 . That is, the more details reported about a trip in Phase 1, the less likely that new information can be reported in Phase 2. We therefore included the amount of information reported in Phase 1 as a covariate in the Phase 2 analyses. 
Second, the Phase factor included a confound. The difference between the two phases was not only the Sketching manipulation (present in Phase 2 and absent in Phase 1), but also the type of question asked (an open recall format in Phase 1 and a more specific questioning format in Phase 2). This change was necessary for the sketch manipulation. Someone can only make a sketch of particular moments in a trip, not of the entire trip, as that would result in interviewees requesting to sketch a cartoon (sequence after sequence). Third, we did not expect any differences between Phases 1 and 2 for the Veracity and Interpreter factors, the only two factors that were manipulated in both phases. In fact, we found little differences in the Veracity and Interpreter effects between the two phases. For Veracity, the only difference was that the self-handicapping strategies effects was not significant in Phase 2, event 1 , a finding we cannot explain. For the Interpreter effects, the only differences were that the total details effect was not significant in Phase 2, event 1 and that the complications effect was not significant in Phase 2, events 2-4. Again, findings we cannot explain.

\section{Conclusion}

The interpreter-absent interviews resulted in more details than the interpreter-present interviews, because interviewees reported fewer details in interpreter-present interviews than in interpreter-absent interviews. Since gathering information is a main aim in investigative interviews, practitioners are advised to take this negative effect into account when deciding to use interpreters in interviews. In terms of interviewees' responses, the proportion of complications variable discriminated truth tellers from liars better than total details. This was the case in both interpreter-absent and interpreter-present interviews, contributing to the growing evidence that the proportion of complications is a diagnostic indicator of veracity. Unlike in previous research, drawing did not facilitate recall or lie detection, possibly due to the way the request to sketch was introduced in the experiment. 


\section{Acknowledgements}

This work is funded by the High-Value Detainee Interrogation Group, DJF-15-1299V-0010271 awarded to the University of Portsmouth (UK). Any opinions, findings, conclusions, or recommendations expressed in this article are those of the authors and do not necessarily reflect the views of the U.S. Government.

\section{Data Availability Statement}

The data that support the findings of this study are available from the corresponding author upon reasonable request. (CBCA) reality criteria in adults: A meta-analytic review. International Journal of Clinical and Health Psychology, 16, 201-210. doi.org/10.1016/j.ijchp.2016.01.002

Cialdini, R. B. (2007) Influence: The psychology of persuasion. New York: William Morrow and Company.

Dando, C., Wilcock, R., \& Milne, R. (2009). The Cognitive Interview: The efficacy of a modified mental reinstatement of context procedure for frontline police investigators. Applied Cognitive Psychology, 23, 138-147. doi: 10.1002/acp.1451

DePaulo, B. M., Kashy, D. A., Kirkendol, S. E., Wyer, M. M., \& Epstein, J. A. (1996). Lying in everyday life. Journal of Personality and Social Psychology, 70, 979-995. Doi: $10.1037 / 0022-3514.70 .5 .979$

DePaulo, B. M., Lindsay, J. L., Malone, B. E., Muhlenbruck, L., Charlton, K., \& Cooper, H. (2003). Cues to deception. Psychological Bulletin, 129, 74-118. Doi: 10.1037/00332909.129.1.74

Ewens, S., Vrij, A., Leal, S., Mann, S., Jo, E., \& Fisher, R. P. (2016a). The effect of interpreters on eliciting information, cues to deceit and rapport. Legal and Criminological Psychology, 21, 286-304 DOI: 10.1111/lcrp.12067 
Ewens, S., Vrij, A., Leal, S., Mann, S., Jo, E., \& Houston, K. (2017). The effect of the presence and seating position of an interpreter on eliciting information and cues to deceit. Psychology, Crime, \& Law, 23, 180-200.

doi:10.1080/1068316X.2016.1239100

Ewens, S., Vrij, A., Leal, S., Mann, S., Jo, E., Shaboltas, A., Ivanova, M., Granskaya, J., \& Houston, K. (2016b). Using the model statement to elicit information and cues to deceit from native speakers, non-native speakers and those talking through an interpreter. Applied Cognitive Psychology, 30, 854-862. DOI: 10.1002/acp.3270

Faul, F., Erdfelder, E., Lang, A.-G., \& Buchner, A. (2007). G*Power 3: A flexible statistical power analysis program for the social, behavioral, and biomedical sciences. Behavior Research Methods, 39(2), 175-191. Doi: 10.3758/BF03193146

Hartwig, M., Granhag, P. A., \& Luke, T. (2014). Strategic use of evidence during investigative interviews: The state of the science. In: Raskin, D.C., Honts, C.R., Kircher, J.C. (Eds.), Credibility Assessment: Scientific Research and Applications (pp. 1-36). Oxford, UK: Academic Press.

Hartwig, M., Granhag, P. A., \& Strömwall, L. (2007). Guilty and innocent suspects’ strategies during interrogations. Psychology, Crime, \& Law, 13, 213-227, doi: $10.1080 / 10683160600750264$.

Houston, K. A., Russano, M. B., \& Ricks, E. P. (2017). 'Any friend of yours is a friend of mine': Investigating the utilization of an interpreter in an investigative interview. Psychology, Crime, \& Law, 23, 413-426. Doi: 10.1080/1068316X.2017.1290091

Köhnken, G. (2004). Statement Validity Analysis and the 'detection of the truth'. In P. A. Granhag \& L. A. Strömwall (Eds.), Deception detection in forensic contexts (pp. 41-63). Cambridge, England: Cambridge University Press. 
Leal, S., Vrij, A., Warmelink, L., Vernham, Z., \& Fisher, R. (2015). You cannot hide your telephone lies: Providing a model statement as an aid to detect deception in insurance telephone calls. Legal and Criminological Psychology, 20, 129-146.

Doi: $10.1111 /$ lcrp.12017

Leins, D., Fisher, R. P., Pludwinsky, L., Robertson, B., \& Mueller, D.H. (2014). Interview protocols to facilitate human intelligence sources' recollections of meetings. Applied Cognitive Psychology, 28, 926-935. DOI: 10.1002/acp.304

Masip, J., Sporer, S., Garrido, E., \& Herrero, C. (2005). The detection of deception with the reality monitoring approach: A review of the empirical evidence. Psychology, Crime, \& Law, 11, 99-122. Doi: 10.1080/10683160410001726356

Mattison, M. C. L., Dando, C. J., \& Ormerod, T. C. (2015). Sketching to remember: Episodic free recall task support for child witnesses and victims with autism spectrum disorder. Journal of Autism and Developmental Disorders, 45, 1751-1765. Doi: DOI 10.1007/s10803-014-2335-z

Nahari, G., Vrij, A., \& Fisher, R. P. (2014). Exploiting liars' verbal strategies by examining the verifiability of details. Legal and Criminological Psychology, 19, 227-239.

Doi: $10.1111 / \mathrm{j} .2044-8333.2012 .02069 . x$

Nelson, D. L., \& Goodmon, L. B. (2003). Disrupting attention: The need for retrieval cues in working memory theories. Memory and Cognition, 31, 65-76. Doi:

\subsection{8/BF03196083}

Oberlader, V. A., Naefgen, C., Koppehele-Gossel, J., Quinten, L., Banse, R., \& Schmidt, A. F. (2016). Validity of content-based techniques to distinguish true and fabricated statements: A meta-analysis. Law and Human Behavior, 1-63. Doi:

10.1037/lhb0000193 
Russano, M. B., Narchet, F. M., \& Kleinman, S. M. (2014). Analysts, interpreters and intelligence interrogations: Perceptions and insights. Applied Cognitive Psychology, 28: 829-846. DOI: 10.1002/acp.3070

Russano, M. B., Narchet, F. M., Kleinman, S. M., \& Meissner, C. M. (2014). Structured interviews of experienced HUMINT interrogators. Applied Cognitive Psychology, 28, 847-859. DOI: $10.1002 /$ acp.3069

Vallano, J., P. \& Schreiber Compo, N. (2011). A comfortable witness is a good witness: Rapport-building and susceptibility to mis-information in an investigative mock-crime interview. Applied Cognitive Psychology, 25, 960-970. DOI: 10.1002/acp.1789 Viezzi, M. (2012). Simultaneous and consecutive interpreting (non-conference settings). In C. Millan \& F. Bartrina, (Ed.) The Routledge handbook of translation studies, (pp. 377-388). Abingdon: Routledge.

Vrij, A. (2008). Detecting lies and deceit: Pitfalls and opportunities, second edition. Chichester: John Wiley and Sons.

Vrij, A., Fisher, R., Blank, H. (2017). A cognitive approach to lie detection: A meta-analysis. Legal and Criminological Psychology, 22, 1-21. DOI:10.1111/lcrp.12088

Vrij, A., \& Granhag, P. A. (2012). Eliciting cues to deception and truth: What matters are the questions asked. Journal of Applied Research in Memory and Cognition, 1, 110-117. doi.org/10.1016/j.jarmac.2012.02.

Vrij, A., Fisher, R., Blank, H. (2017). A cognitive approach to lie detection: A meta-analysis. Legal and Criminological Psychology, 22, 1-21. DOI:10.1111/lcrp.12088

Vrij, A., Leal, S., \& Fisher, R. P. (2018). Verbal deception and the Model Statement as a lie detection tool. Manuscript under review.

Vrij, A., Leal, S., Fisher, R. P., Mann, S., Dalton, G. Jo, E., Shaboltas, A., Khaleeva, M., Granskaya, J., \& Houston, K. (2018a). Sketching as a technique to elicit information 
and cues to deceit in interpreter-based interviews. Journal of Applied Research in Memory and Cognition, 7, 303-313. Doi: 10.1016/j.jrarmac.2017.11.001

Vrij, A., Leal, S., Jupe, L., \& Harvey, A. (2018b). Within-subjects verbal lie detection measures: A comparison between total detail and proportion of complications. Legal and Criminological Psychology. Doi:10.1111/lcrp.12126

Vrij, A., Leal, S., Mann, S., Dalton, G. Jo, E., Shaboltas, A., Khaleeva, M., Granskaya, J., \& Houston, K. (2017). Using the Model Statement to elicit information and cues to deceit in interpreter-based interviews. Acta Psychologica, 177, 44-53. Doi: 10.1016/j.actpsy.2017.04.011

Vrij, A., Leal, S., Mann, S., Fisher, R. P., Dalton, G. Jo, E., Shaboltas, A., Khaleeva, M., Granskaya, J., \& Houston, K. (2018c). Using unexpected questions to elicit information and cues to deceit in interpreter-based interviews. Applied Cognitive Psychology, 32, 94-104. Doi: 10.1002/acp.3382 
Table 1. Statistical Results as a Function of Veracity

\begin{tabular}{|c|c|c|c|c|c|c|c|c|}
\hline \multirow{2}{*}{ 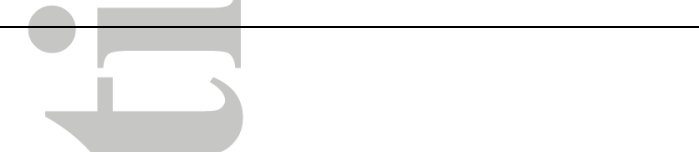 } & \multicolumn{2}{|c|}{ Truth } & \multicolumn{2}{|c|}{ Lie } & \multirow{2}{*}{$\boldsymbol{F}$} & \multirow{2}{*}{$p$} & \multicolumn{2}{|c|}{ Cohen's $d$} \\
\hline & $M(S D)$ & $95 \% \mathrm{CI}$ & $M(S D)$ & $95 \% \mathrm{CI}$ & & & $d$ & $95 \% \mathrm{CI}$ \\
\hline Preparation thoroughness & $04.67(01.18)$ & $04.44,04.90$ & $04.30(01.17)$ & $04.08,04.53$ & 05.05 & .026 & 0.31 & $0.03,0.59$ \\
\hline Preparation time & $06.07(01.13)$ & $05.80,06.34$ & $05.35(01.62)$ & $05.08,05.62$ & 13.59 & $<.001$ & 0.52 & $0.23,0.79$ \\
\hline Percentage truth telling & $94.20(12.20)$ & $90.17,98.29$ & $21.78(26.66)$ & $17.77,25.84$ & 623.02 & $<.001$ & 3.49 & $3.00,3.87$ \\
\hline Number of key words written down & $04.90(02.62)$ & $04.37,05.42$ & $04.84(02.78)$ & $04.31,05.35$ & 00.03 & .863 & 0.02 & $-.25,0.30$ \\
\hline $\begin{array}{l}\text { Number of events reported } \\
\text { Phase } 1(\mathbf{N}=\mathbf{2 0 5})\end{array}$ & $02.44(00.89)$ & $02.29,02.60$ & $02.49(00.77)$ & $02.33,02.64$ & 00.14 & .708 & 0.06 & $-.22,0.33$ \\
\hline Number of details (total details) & $39.15(23.22)$ & $35.89,43.52$ & $34.51(15.75)$ & $30.25,37.85$ & 04.13 & .043 & 0.23 & $-0.05,0.51$ \\
\hline Number of complications & $05.50(06.91)$ & $04.44,06.43$ & $02.00(02.35)$ & $01.11,03.09$ & 21.05 & $<.001$ & 0.68 & $0.39,0.95$ \\
\hline Number of common knowledge details & $03.82(02.69)$ & $03.30,04.34$ & $04.71(02.52)$ & $04.20,05.23$ & 05.60 & .019 & 0.34 & $0.06,0.61$ \\
\hline Number of self-handicapping strategies & $00.16(00.44)$ & $00.04,00.27$ & $00.35(00.68)$ & $00.24,00.46$ & 05.57 & .019 & 0.33 & $0.05,0.60$ \\
\hline $\begin{array}{l}\text { Proportion of complications } \\
\text { Phase 2, event } 1(\mathbf{N}=\mathbf{2 0 5})\end{array}$ & $00.47(00.34)$ & $00.42,00.54$ & $00.26(00.27)$ & $00.19,00.31$ & 26.97 & $<.001$ & 0.68 & $0.39,0.96$ \\
\hline Number of new details (total new details) & $10.62(08.49)$ & $09.19,12.00$ & $07.54(05.30)$ & $06.21,09.00$ & 08.47 & $<.001$ & 0.44 & $0.15,0.58$ \\
\hline Number of new complications & $02.37(02.82)$ & $01.89,02.77$ & $01.20(01.47)$ & $00.82,01.69$ & 11.10 & $<.001$ & 0.52 & $0.24,0.79$ \\
\hline Number of new common knowledge details & $00.17(00.47)$ & $00.07,00.31$ & $00.54(00.72)$ & $00.40,00.64$ & 13.33 & $<.001$ & 0.61 & $0.32,0.88$ \\
\hline Number of new self-handicapping strategies & $00.02(00.14)$ & $-.0 .04,00.08$ & $00.09(00.37)$ & $00.03,00.15$ & 02.84 & .094 & 0.25 & $-0.03,0.52$ \\
\hline Proportion of complications & $00.80(00.33)$ & $00.73,00.87$ & $00.58(00.38)$ & $00.52,00.66$ & 16.31 & $<.001$ & 0.62 & $0.33,0.89$ \\
\hline
\end{tabular}

This article is protected by copyright. All rights reserved. 
Phase 2, events 2-4 $(\mathrm{N}=184)$

Number of new details (total new details)

Number of new complications

$11.50(10.49) \quad 09.28,13.01$

$03.19(03.49) \quad 02.52,03.72$

$00.16(00.48) \quad 00.01,00.36$

$00.01(00.11)$

$00.86(00.27)$

$-0.05,00.05$

Number of new self-handicapping strategies

Proportion of complications

$07.45(06.71)$

$05.89,09.43$

06.77

.010

0.46

$0.16,0.75$

$01.40(01.84)$

$00.88,02.02 \quad 14.89$

$<.001$

0.65

$0.34,0.94$

$00.69(01.00)$

$00.50,00.83 \quad 14.86$

$<.001$

0.67

$0.36,0.95$

00.07 (00.30)

$00.04,00.13$

05.02

.018

0.26

$-.03,0.55$

$00.55(00.39)$

$00.48,00.62$

35.53

$<.001$

0.92

$0.60,1.21$

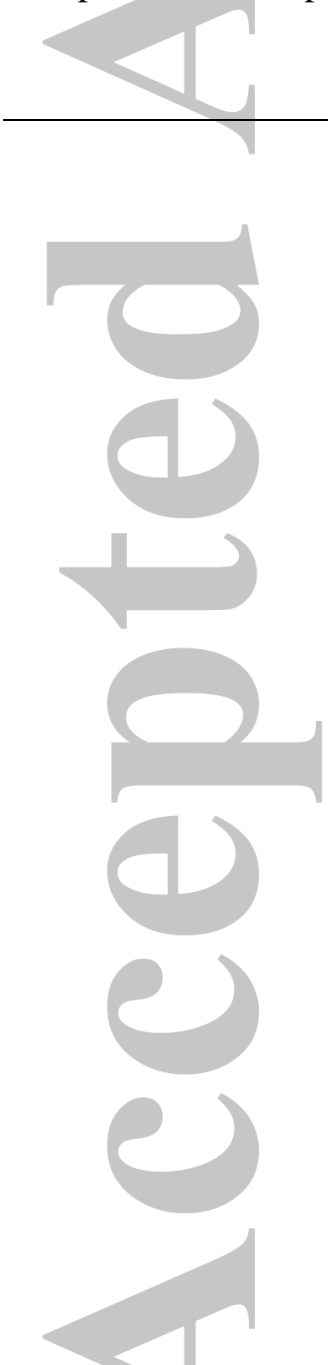


Table 2. Statistical Results as a Function of Interpreter

\begin{tabular}{|c|c|c|c|c|c|c|c|c|}
\hline & \multicolumn{2}{|c|}{ Interpreter absent } & \multicolumn{2}{|c|}{ Interpreter present } & \multirow{2}{*}{$\boldsymbol{F}$} & \multirow{2}{*}{$p$} & \multicolumn{2}{|c|}{ Cohen's $d$} \\
\hline & $M(S D)$ & $95 \% \mathrm{CI}$ & $M(S D)$ & $95 \% \mathrm{CI}$ & & & $d$ & 95\% CI \\
\hline Motivation to perform well & $03.86(00.68)$ & $03.72,04.00$ & $04.13(00.72)$ & $04.00,04.27$ & 07.47 & .007 & 0.39 & $0.10,0.66$ \\
\hline Rapport & $05.36(00.84)$ & $05.19,05.52$ & $05.60(00.85)$ & $05.44,05.77$ & 04.36 & .038 & 0.28 & $0.00,0.58$ \\
\hline Number of key words written down & $04.49(02.18)$ & $03.96,05.00$ & $05.24(03.08)$ & $04.73,05.76$ & 04.16 & .043 & 0.28 & $0.00,0.58$ \\
\hline Number of events reported & $02.58(00.80)$ & $02.43,02.75$ & $02.35(00.83)$ & $02.18,02.49$ & 05.04 & .026 & 0.28 & $0.00,0.58$ \\
\hline \multicolumn{9}{|l|}{ Phase $1(N=205)$} \\
\hline Number of details (total details) & $39.31(21.34)$ & $35.81,43.44$ & $34.40(18.18)$ & $30.47,37.89$ & 03.98 & .047 & 0.25 & $-.03,0.52$ \\
\hline Number of complications & $04.58(06.77)$ & $03.75,05.74$ & $02.92(03.55)$ & $01.81,03.77$ & 07.39 & .007 & 0.31 & $0.03,0.58$ \\
\hline Number of common knowledge details & $04.29(02.32)$ & $03.74,04.78$ & $04.25(02.92)$ & $03.76,04.79$ & 00.01 & .973 & 0.02 & $-0.26,0.29$ \\
\hline Number of self-handicapping strategies & $00.34(00.65)$ & $00.22,00.44$ & $00.17(00.49)$ & $00.07,00.29$ & 03.55 & .061 & 0.30 & $0.02,0.57$ \\
\hline Proportion of complications & $00.38(00.32)$ & $00.33,00.45$ & $00.35(00.33)$ & $00.28,00.40$ & 01.06 & .306 & 0.09 & $-0.18,0.36$ \\
\hline \multicolumn{9}{|l|}{ Phase 2, event $1(N=205)$} \\
\hline Number of new details (total new details) & $09.48(07.85)$ & $08.09,10.90$ & $08.68(06.57)$ & $07.32,10.08$ & 00.61 & .434 & 0.11 & $-0.17,0.38$ \\
\hline Number of new complications & $02.19(02.72)$ & $01.70,02.58$ & $01.39(01.76)$ & $01.01,01.88$ & 04.77 & .030 & 0.35 & $0.07,0.62$ \\
\hline Number of common knowledge details & $00.34(00.57)$ & $00.25,00.49$ & $00.38(00.70)$ & $00.22,00.46$ & 00.10 & .756 & 0.06 & $-.21,0.34$ \\
\hline Number of self-handicapping strategies & $00.08(00.37)$ & $00.03,00.14$ & $00.03(00.17)$ & $-0.03,00.81$ & 01.84 & .177 & 0.17 & $-.10,0.45$ \\
\hline $\begin{array}{l}\text { Proportion of complications } \\
\text { Phase 2, events 2-4 }(N=184)\end{array}$ & $00.70(00.38)$ & $00.61,00.75$ & $00.69(00.37)$ & $00.64,00.78$ & 00.23 & .633 & 0.03 & $-.25,0.30$ \\
\hline
\end{tabular}

This article is protected by copyright. All rights reserved. 
Number of new details (total new details)

Number of new complications

Number of new common knowledge details

Number of new self-handicapping strategies

Proportion of complications

$\begin{array}{llllllll}10.95(10.52) & 09.40,12.94 & 07.76(06.58) & 05.80,09.46 & 07.25 & .008 & 0.36 & 0.07,0.65 \\ 02.43(03.32) & 01.95,03.09 & 02.08(02.37) & 01.46,02.64 & 01.20 & .274 & 0.12 & -.17,0.41 \\ 00.51(00.98) & 00.34,00.67 & 00.36(00.64) & 00.18,00.51 & 01.70 & .194 & 0.18 & -.11,0.47 \\ 00.05(00.27) & 00.01,00.10 & 00.03(00.18) & -0.02,00.08 & 00.66 & .417 & 0.09 & -.20,0.37 \\ 00.69(00.34) & 00.63,00.77 & 00.71(00.39) & 00.65,00.79 & 00.19 & .664 & 0.05 & -.24,0.34\end{array}$

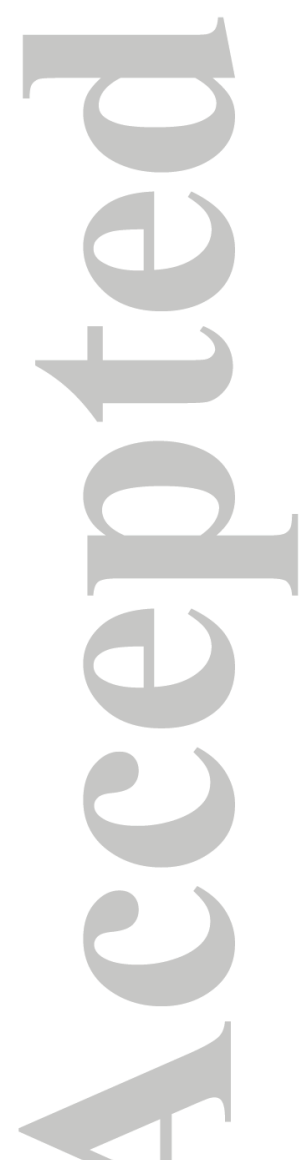


Table 3. Statistical Results for the Interpreter Text and Interviewee Text comparison

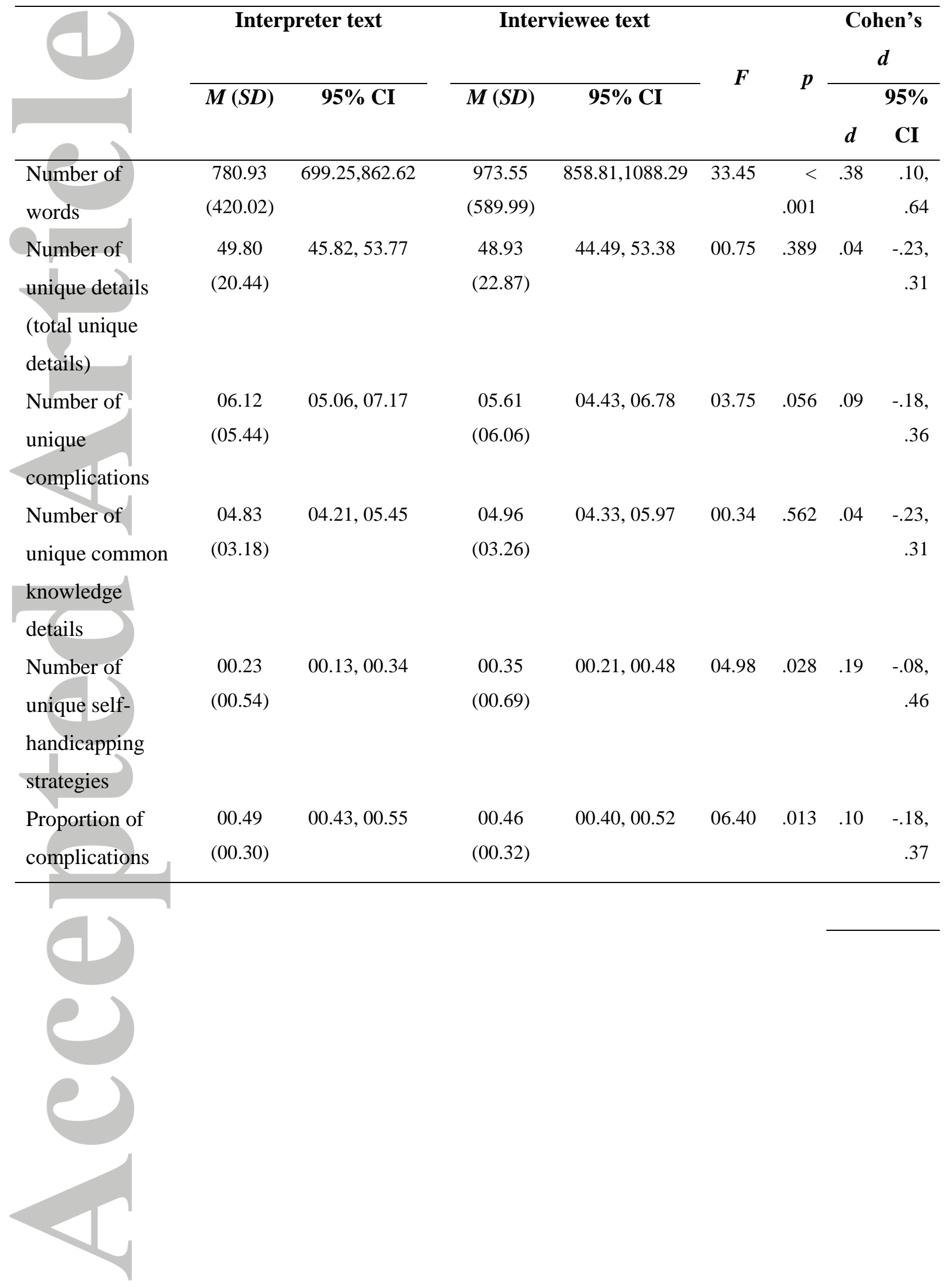


Table 4. Statistical Results for the Interpreter Absent and Interpreter Text comparison

\begin{tabular}{|c|c|c|c|c|c|c|c|c|}
\hline & \multicolumn{2}{|c|}{ Truth } & \multicolumn{2}{|c|}{ Lie } & \multirow{2}{*}{$\boldsymbol{F}$} & \multirow{2}{*}{$p$} & \multicolumn{2}{|c|}{ Cohen's $d$} \\
\hline & $M(S D)$ & $95 \% \mathrm{CI}$ & $M(S D)$ & $95 \% \mathrm{CI}$ & & & $d$ & 95\% CI \\
\hline Number of words & $1011.62(811.46)$ & $855.93,1127.16$ & $860.88(580.37)$ & $752.70,1021.66$ & 01.12 & .290 & .21 & $-.06, .49$ \\
\hline Number of unique details (total unique details) & $59.69(27.85)$ & $55.47,64.58$ & $49.00(18.44)$ & $44.20,53.47$ & 10.88 & .001 & .45 & $.17, .72$ \\
\hline Number of unique complications & $10.63(09.84)$ & $09.14,12.02$ & $04.60(03.98)$ & $03.28,06.15$ & 31.05 & $<.001$ & .80 & $.51,1.08$ \\
\hline Number of unique common knowledge details & $04.08(02.80)$ & $03.52,04.64$ & $05.59(02.82)$ & $05.04,6.15$ & 13.83 & $<.001$ & .54 & $.25, .81$ \\
\hline Number of unique self-handicapping strategies & $00.19(00.48)$ & $00.03,00.33$ & $00.50(00.99)$ & $00.36,00.67$ & 09.12 & .003 & .40 & $.12, .67$ \\
\hline \multirow[t]{3}{*}{ Proportion of complications } & $00.63(00.29)$ & $00.58,00.68$ & $00.39(00.26)$ & $00.33,00.44$ & 39.23 & $<.001$ & .87 & $.57,1.14$ \\
\hline & \multicolumn{2}{|c|}{ Interpreter absent } & \multicolumn{2}{|c|}{ Interpreter text } & \multirow{2}{*}{$\boldsymbol{F}$} & \multirow{2}{*}{$p$} & \multicolumn{2}{|c|}{ Cohen's $d$} \\
\hline & $M(S D)$ & $95 \% \mathrm{CI}$ & $M(S D)$ & $95 \% \mathrm{CI}$ & & & $d$ & 95\% CI \\
\hline Number of words & $1095.44(887.62)$ & $985.60,1256.74$ & $780.93(420.02)$ & $623.49,890.62$ & 13.83 & $<.001$ & .46 & $.17, .73$ \\
\hline Number of unique details (total unique details) & $58.97(26.75)$ & $55.03,64.23$ & $49.80(20.44)$ & $44.69,53.76$ & 09.79 & .002 & .39 & $.10, .66$ \\
\hline Number of unique complications & $09.13(09.87)$ & $07.99,10.87$ & $06.12(05.44)$ & $04.44,07.28$ & 11.75 & .001 & .38 & $.10, .65$ \\
\hline Number of unique common knowledge details & $04.85(02.61)$ & $04.27,05.39$ & $04.83(03.18)$ & $04.29,05.39$ & 00.01 & .973 & .01 & $-.27, .28$ \\
\hline Number of unique self-handicapping strategies & $00.47(00.98)$ & $00.31,00.62$ & $00.23(00.54)$ & $00.08,00.38$ & 04.55 & .034 & .30 & $.02, .58$ \\
\hline Proportion of complications & $00.52(00.30)$ & $00.47,00.58$ & $00.49(00.30)$ & $00.43,00.54$ & 01.09 & .297 & . 10 & $-.18, .37$ \\
\hline
\end{tabular}

This article is protected by copyright. All rights reserved. 
Table 5. Statistical Results for the Interpreter Absent and Interviewee Text comparison

\begin{tabular}{|c|c|c|c|c|c|c|c|c|}
\hline & \multicolumn{2}{|c|}{ Truth } & \multicolumn{2}{|c|}{ Lie } & \multirow{3}{*}{$\boldsymbol{F}$} & \multirow{3}{*}{$p$} & \multicolumn{2}{|c|}{ Cohen's $d$} \\
\hline & \multirow[t]{2}{*}{$M(S D)$} & \multirow[t]{2}{*}{ 95\% CI } & \multirow[t]{2}{*}{$M(S D)$} & \multirow[t]{2}{*}{$95 \% \mathrm{CI}$} & & & \multirow[b]{2}{*}{$d$} & $95 \%$ \\
\hline & & & & & & & & CI \\
\hline Number of words & $1127.40(871.54)$ & $957.75,1248.83$ & $940.71(601.44)$ & $822.76,1112.48$ & 01.63 & .203 & .03 & $-.24, .30$ \\
\hline \multicolumn{9}{|l|}{ unique details) } \\
\hline Number of unique complications & $10.22(10.36)$ & $08.68,11.70$ & $04.50(04.00)$ & $03.09,06.10$ & 25.74 & $<.001$ & .73 & $.44,1.00$ \\
\hline Number of unique common & $04.17(02.80)$ & $03.67,04.77$ & $05.64(02.93)$ & $05.04,06.13$ & 11.79 & .001 & .51 & $.23, .78$ \\
\hline \multicolumn{9}{|l|}{ knowledge details } \\
\hline Number of unique self- & $00.25(00.57)$ & $00.10,00.43$ & $00.55(01.03)$ & $00.38,00.71$ & 05.61 & .019 & .36 & $.08, .63$ \\
\hline \multicolumn{9}{|l|}{ handicapping strategies } \\
\hline \multirow{4}{*}{ Proportion of complications } & $00.60(00.30)$ & $00.54,00.66$ & $00.38(00.27)$ & $00.32,00.43$ & 30.27 & $<.001$ & .77 & $.48,1.04$ \\
\hline & \multicolumn{2}{|c|}{ Interpreter absent } & \multicolumn{2}{|c|}{ Interviewee text } & \multirow{3}{*}{$\boldsymbol{F}$} & \multirow{3}{*}{$p$} & \multicolumn{2}{|c|}{ Cohen's $d$} \\
\hline & $M(S D)$ & $95 \% \mathrm{CI}$ & $M(S D)$ & $95 \% \mathrm{CI}$ & & & & $95 \%$ \\
\hline & & & & & & & $d$ & CI \\
\hline Number of words & $1095.44(887.62)$ & $985.60,1256.74$ & 973.55 (589.99) & $802.89,1089.57$ & 02.89 & .091 & .16 & $-.11, .43$ \\
\hline $\begin{array}{l}\text { Number of unique details (total } \\
\text { unique details) }\end{array}$ & $58.97(26.75)$ & $55.03,64.23$ & $48.93(22.87)$ & $43.71,53.16$ & 10.33 & .002 & .40 & $.12, .67$ \\
\hline Number of unique complications & $09.13(09.87)$ & $07.99,10.87$ & $05.61(06.06)$ & $03.90,06.88$ & 04.64 & .032 & .43 & $.15, .70$ \\
\hline
\end{tabular}

This article is protected by copyright. All rights reserved. 
Number of unique common

knowledge details

Number of unique self-

handicapping strategies

Proportion of complications
$04.85(02.61)$

00.47 (00.98)

$00.52(00.30)$
$04.27,05.39$

$00.31,00.62$

$00.47,00.58$
$04.96(03.26)$

00.35 (00.69)

$00.19,00.52$

01.86

.174

.14

$-.13, .41$

$00.39,00.50$

00.01

$.973 \quad .19 \quad-.08, .46$

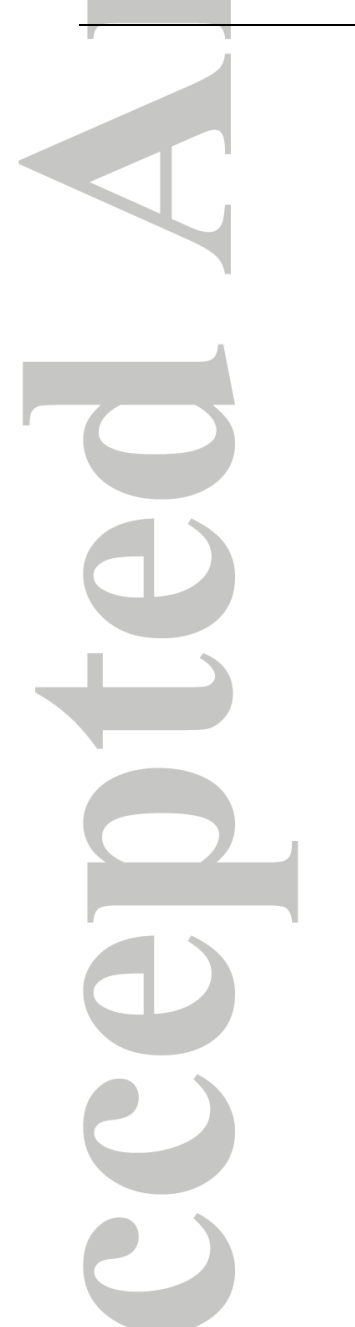


Table 6. Statistical Results for the Veracity $x$ Interpreter Interaction

\begin{tabular}{|c|c|c|c|c|c|c|c|c|c|}
\hline & \multicolumn{2}{|c|}{ Interpreter absent } & \multicolumn{2}{|c|}{ Interpreter text } & \multirow{2}{*}{$\boldsymbol{F}$} & \multirow{2}{*}{$p$} & \multicolumn{2}{|c|}{ Cohen's $d$} & \\
\hline & $M(S D)$ & $95 \% \mathrm{CI}$ & $M(S D)$ & $95 \% \mathrm{CI}$ & & & $d$ & $95 \% \mathrm{CI}$ & \\
\hline Number of unique complications: Truth tellers & $13.24(12.10)$ & $10.88,16.33$ & $08.12(06.15)$ & $05.09,10.44$ & 08.98 & .003 & .54 & $.13, .92$ & 5.17 \\
\hline \multirow[t]{3}{*}{ Number of unique complications: Liars } & $05.10(04.22)$ & $04.14,06.41$ & $04.12(03.70)$ & $02.86,05.08$ & 02.46 & .120 & .25 & $-.14, .63$ & 0.42 \\
\hline & \multicolumn{2}{|c|}{ Interpreter absent } & \multicolumn{2}{|c|}{ Interviewee text } & & & & & \\
\hline & $\mathbf{M}(\mathbf{S D})$ & $95 \% \mathrm{CI}$ & $\mathbf{M}(\mathbf{S D})$ & $95 \% \mathrm{CI}$ & $\boldsymbol{F}$ & $p$ & $d$ & $95 \% \mathrm{CI}$ & \\
\hline Number of unique complications: Truth tellers & $13.24(12.10)$ & $10.88,16.33$ & $07.31(07.38)$ & $04.26,09.89$ & 09.73 & .002 & .59 & $.19, .98$ & 16.81 \\
\hline Number of unique complications: Liars & $05.10(04.22)$ & $04.14,06.41$ & $03.90(03.72)$ & $02.61,04.86$ & 03.49 & .065 & .30 & $-.09, .69$ & 0.58 \\
\hline
\end{tabular}

